\title{
LA MEMORIA DEL LINAJE ANSÚREZ: EL SEPULCRO DE FERNANDO PÉREZ EN GORDALIZA DEL PINO (LEÓN)
}

\author{
MEMORY LINEAGE OF ANSÚREZ: THE FUNERARY \\ MONUMENT IN GORDALIZA DEL PINO (LEÓN)
}

\author{
María Encarnación MARTÍN LÓPEZ \\ Universidad de León
}

\begin{abstract}
Resumen: El hallazgo de la pintura mural en los muros de la iglesia parroquial de Santa María de Arbas de la localidad leonesa de Gordaliza del Pino ha sido toda una revelación. El monumento funerario del llamado caballero de Gordaliza, además de su valor artístico, posee un valor histórico que trataremos de reflejar en este estudio y que despeja algunas incógnitas sobre la historia del reino de León, y concretamente sobre el linaje de los Ansúrez.

Palabras clave: pintura medieval, epigrafía medieval, genealogía, linajes castellanos, escritura gótica minúscula, historia medieval.
\end{abstract}

\begin{abstract}
The discovery of the mural on the walls of the church of Santa Maria de Arbas of the town of Leon Gordaliza del Pino has been a revelation. The funerary monument called Knight Gordaliza addition to its artistic value, has a historical value that try to reflect in this study and that clears some questions about the history of the kingdom of Leon, and specifically about the lineage of Ansúrez.
\end{abstract}

Keywords: medieval painting, medieval epigraphy, genealogy, Castilian lineages, tiny Gothic script, medieval history.

El hallazgo de la denominada "pintura del Caballero" en la iglesia de Nuestra Señora de Arbas, en Gordaliza del Pino (León), tuvo lugar en 2011 al realizar labores de conservación sobre un retablo que se encontraba en el muro sur de la mencionada iglesia. Al iniciar el estudio se apreció sobre el muro la existencia de unas pinturas murales de notable valor, de manera que el responsable de patrimonio del Obispado de León, Máximo Rascón, decidió desmontar el bien mueble para inspeccionar la pared oculta por el retablo. Se descubrió así un arcosolio funerario formado por la sepultura, un retrato del caballero difunto y una inscripción 


\section{MARÍA ENCARNACIÓN MARTÍN LÓPEZ

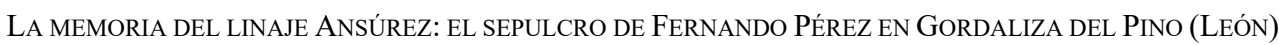

en la parte superior. Las obras de restauración de la pintura mural se iniciaron inmediatamente al constatar el valor de las mismas dejando al descubierto el monumento funerario ${ }^{1}$. La necesidad de leer la inscripción para la identificación del personaje fue inmediata solo que la información que daba no hizo más que abrir nuevos interrogantes respecto a quién pertenecía la sepultura, por qué y quién la hizo y qué relación tenía el personaje con la villa de Gordaliza.

Gordaliza del Pino (León) es una pequeña población situada en plena Tierra de Campos, al suroeste de la provincia, muy cerca de Sahagún. En los siglos XI y XII la villa se vincula a la abadía benedictina de Sahagún ${ }^{2}$ y a linajes como los Alfonso y los Ansúrez. Su relación con el linaje Ansúrez se inicia en 1090 año en que se data un pleito entre el conde Pedro Ansúrez, con la villa sobre varias propiedades en el mismo territorio. El pleito concluye con un acuerdo en que Ansúrez cede al monasterio la mitad de Fuentecillas, Gordaliza y Vallecillo ${ }^{3}$. Tan importante como la presencia nobiliar será la eclesiástica ya que tanto la Iglesia de León como el monasterio de Sahagún así como la orden de San Juan de Jerusalen tendrán propiedades en esta villa. El padre Risco nos hace referencia, además, de un documento de donación del conde entre 1088-1091 a favor de la iglesia de León y su obispo Pedro de varias heredades que había comprado a la condesa Justa en Fuentes de Valdepero, Fuentes de Verroz, identificado como Fuentes de Villalón, y en Gordaliza ${ }^{4}$. La orden de San Juan de Jerusalén también tenía propiedades en la villa en el siglo XIII. Finalmente, en el libro de presentaciones se nos dice que a mediados del XIV era lugar de doña Juana y su hijo Diego Ramírez .

\footnotetext{
${ }^{1}$ La recuperación y restauración de las pinturas se deben a José Luis González Santos a quien agradezco los datos sobre la intervención.

${ }^{2}$ En 1083 la condesa Momadona dona al monasterio numerosos bienes en diferentes localidades entre ellas, Gordaliza ( $n^{\circ}$ 806). En 1096 Miguel Cristóforez dona al monasterio un solar que había recibido de la condensa Ildonza un año antes en Gordaliza ( $n^{\circ}$ 963) En 1098 el presbítero dona la heredad que tenía en dicho lugar (no 1027). Cf. M. HERRERO DE LA FUENTE, Colección diplomática del monasterio de Sahagún (857-1230), III (1073-1109), Colección Fuentes y estudios de historia leonesa, $\mathrm{n}^{\circ}$ 37, León, 1988.

${ }^{3}$ Cf. M. HERRERO DE LA FUENTE, Colección diplomática del monasterio de Sahagún, $\mathrm{n}^{\circ}$ 867, pp. 176-177.

4 "Et adhuc concedo in uilla que uocatur Gordariza de Illis Matis illam diuisionem qui fuit de mea muliere comitissa domna Eilo cum monasterio Sancti Martini cum ómnibus suis appendiciis". Cf. M. RISCO, ES, XXXV, Madrid, 1787, 136. Para Ruiz Asencio la identificación de esta localidad con Gordaliza del Pino es dudosa. Cf. J. M. RUIZ ASENCIO, Colección documental de la catedral de León (775-1230), IV (1032-1109), Colección Fuentes y estudios de historia leonesa $\mathrm{n}^{\mathrm{o}}$ 44, León, 1990, nº 1262, p. 557.

${ }^{5}$ Cf. J. A. FERNÁNDEZ FLÓREZ, "El becerro de presentaciones, cod. 13 del ACL un parroquial leonés de los siglos XIII-XV”, en León y su historia, vol. V, Colección Fuentes y estudios de historia leonesa, $\mathrm{n}^{\circ}$ 32, León, 1984.
} 
En cuanto al edificio, la iglesia parroquial de Nuestra Sra. de Arbas corresponde a la arquitectura románica en ladrillo, propia de la zona. Su parte mejor conservada es la cabecera donde se aprecia un estilo propio del siglo XIII ${ }^{6}$. En las últimas restauraciones se han descubierto varios paños con pinturas de las cuales únicamente podemos contemplar las de la cabecera del ábside del lado del evangelio y el arcosolio del muro sur que vamos a estudiar.

Las pinturas del ábside fueron descubiertas por Gómez Moreno a principios del siglo XX tras el retablo que ocupaba el ábside pero permanecieron ocultas hasta que en 1997 se procedió a retirar el mobiliario para ser restauradas en 2005. El ábside fue rehecho entre los siglos XIV y XV como capilla funeraria. El tema consiste en el ciclo de la vida de San Bartolomé que se desarrolla en el fondo del arcosolio, el Juicio Final en el resto del muro, en la zona superior la figura de Cristo como juez, rodeado de una corte celestial. La parte que rodea el arcosolio se decora con el tema de la resurrección de los muertos y el Juicio de los mismos. Se ejecutó mediante la técnica del óleo y su estilo conjuga reminiscencias del gótico internacional con otros recursos propios de una corriente flamenca, muy del gusto de la Castilla bajomedieval. Los expertos han datado la obra hacia la segunda mitad del siglo XV, concretamente en la década de los setenta, por un taller que había estado en León y conocía la obra pictórica de la catedral y a su maestro Nicolás Francés ${ }^{7}$. Esta cronología se corrobora con la datación de la escritura gótica minúscula de la inscripción que aparece en la línea de la imposta: "Esta obra mandó facer Pero Rodriguez". Pero no son éstas las únicas pinturas existentes en la iglesia: los muros de las naves laterales parecen guardar otros tesoros pictóricos a la espera de una nueva intervención.

El descubrimiento de las pinturas del muro sur del templo no hicieron sino avivar las expectativas de parroquianos y diócesis habida cuenta de la importancia de las ya descubiertas anteriormente. En efecto, las nuevas pinturas murales muestran la presencia de un taller experto que realiza una obra por encargo para ensalzar la figura del yacente situado, a falta de capilla, en un arcosolio en la pared. El conjunto funerario del caballero consiste, pues, en un arcosolio donde se represen-

${ }^{6}$ Cf. Enciclopedia del Románico en León, Aguilar de Campoo, 2002, p. 669.

${ }^{7}$ Quiero agradecer las referencias y análisis de esta obra y su taller a la profesora María del Carmen Rebollo, experta en pintura mural y en Nicolás Francés. Las pinturas del ábside han sido así mismo estudiadas por Luis A. GRAU LOBO, "Murales góticos de la provincia de León: perfil a propósito de algunas novedades", Brigecio: Revista de estudios de Benavente y sus tierras, n. 7 (1997), pp. 123-148. F. GUTIERREZ BAÑOS, "La pintura gótica de la Corona de Castilla en la primera mitad del siglo XV. La recepción de las corrientes internacionales", en La pintura gótica durante el siglo XV en Aragón y otros territorios peninsulares, Zaragoza, 2007, pp. 74-87. 


\section{MARÍA ENCARNACIÓN MARTÍN LÓPEZ \\ LA MEMORIA DEl linAJE ANSÚREZ: El SEPUlCRO DE FERNANDO PÉREZ EN GORdALIZA DEL PINO (LEÓN)}

ta la figura de un joven caballero armado, con inscripción en la parte superior, escrita en gótica minúscula, alusiva al difunto, y un sepulcro sencillo a los pies. Por las características gráficas el conjunto data del último tercio del siglo $\mathrm{XV}$, o principios del XVI, dato que se corrobora con el análisis de la pintura. La inscripción es la única fuente documental que puede ofrecer luz sobre la identificación del yacente. Las condiciones en que se hallaba al ser descubierta apenas permitía leer fragmentos del texto, solo después de las labores de restauración del monumento se ha recuperado la casi totalidad del texto que es el siguiente:

Aquí yace el hijo de don Pedro Ansurez y de la condesa doña Eilo, el cual murió siendo alférez del rey en la guerra, peleando contra los moros; al cual dicho conde don Pedro Ansurez fueron otorgados los derechos y justicias que el rey tenía en este lugar de Gordaliza; y estos sobredichos conde don Pedro Ansurez y condesa Eilo, otorgaron todos los sobredichos derechos así como ellos los tenían al concejo de dicho lugar por el servicio de Dios y en iluminación de su alma. Y mandaron a cualquiera que lo quebrase que sea maldito, excomulgado y condenado con Judas el traidor y diese la saja del cobre por maldición.

Así pues, el monumento sepulcral corresponde a un hijo de Pedro Ansúrez, conde castellano y de su mujer Eylo. La intitulación no identifica directamente al personaje:

Aquí yace el hijo de don Pedro Ansurez y de la condesa doña Eilo, el cual murió siendo alférez del rey en la guerra, peleando contra los moros ${ }^{8}$. El conde Ansúrez solo tuvo dos hijos varones, Alfonso que murió siendo muy joven, y Fernando, último del linaje, que detentó el señorío de Entrepeñas. Así pues, partimos con la hipótesis de identificar al difunto como Fernando Pérez. Ahora bien, este planteamiento inicial nos conduce a cuestionar varios interrogantes: en primer lugar, por qué se hace enterrar a un Ansúrez en una pequeña iglesia como Nuestra Señora de Arbas de Gordaliza y no en un cenobio importante como corresponde al relieve político del linaje; en segundo lugar por qué se hace este nuevo monumento trescientos años después de su muerte, esto es, cual es el motivo de esta renovación sepulcral y, por tanto, cómo fue el sepulcro original; en tercer lugar nos preguntamos en qué contexto histórico se produce esta obra pictórica y quien o

\footnotetext{
${ }^{8}$ En este sentido, tenemos que llamar la atención la importancia que para el autor o autores, o tal vez debamos decir comitentes, del texto y la obra tenía destacar la filiación y no tanto el nombre del difunto. La inscripción comienza con la cláusula notificativa — aquí yace — que debería ir seguida de la intitulación completa con el nombre del difunto. En lugar de éste únicamente se da el dato de la filiación del difunto como hijo de Pedro Ansúrez - “el fyo del conde Pero Ansúrez y de la condesa Eylo" - hecho este que sugiere la importancia que este dato tiene para los comitentes de la inscripción.
} 
quienes fueron los artífices de ésta y de su inscripción y cuáles fueron los motivos que llevaron a contratar un artista y ejecutar una obra de coste considerable.

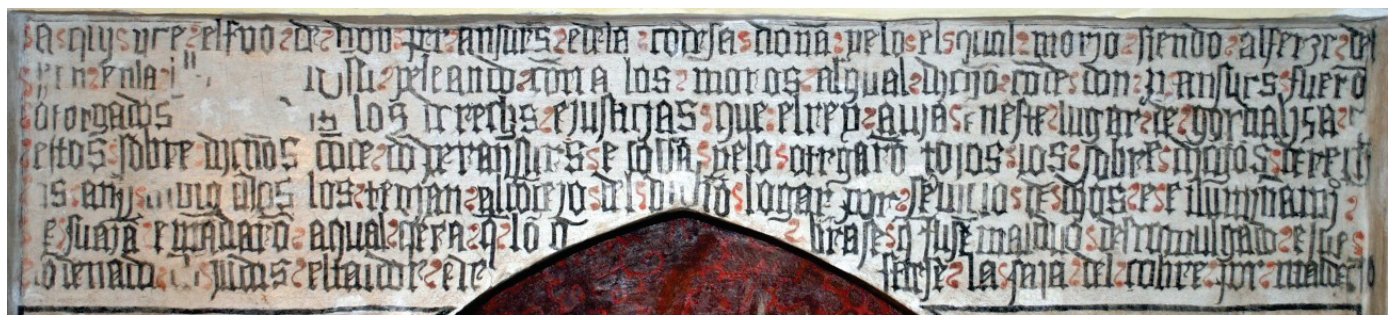

Vista general de la crónica funeraria.

Nuestra investigación pretende responder a todos estos interrogantes planteados, teniendo en cuenta que la principal fuente para responder a todos ellos es la inscripción localizada en la parte superior del arcosolio. Como todas las categorías de fuentes, la epigrafía nos informa sobre la vida social en un momento dado, más en concreto, sobre aquellos que han encargado y ejecutado ${ }^{9}$. En este sentido las peculiaridades que presenta el epígrafe en su forma interna dejan entrever la intención del autor moral del texto e incluso podemos aventurar la identidad de éste. En efecto, si bien inicialmente parece ser un epitafio sepulcral, por presentar su fórmula notificativa la expresión "aquí yace", el análisis detallado del texto nos mostrará lo peculiar de este epitafio.

\section{FERNANDO PEREZ, SU LINAJE, SU MUERTE Y ENTERRA- MIENTO EN GORDALIZA}

Fernando Pérez es el segundo hijo varón del matrimonio del conde Pedro Ansúrez y su mujer Eilo, por tanto descendiente de dos importantes linajes, los Ansúrez y los Alfonso.

\subsection{El linaje Ansúrez-Alfonso}

Pedro Ansúrez era hijo de Ansur Díaz y de su primera mujer, por tanto, del antiguo linaje de los Banu Gómez ${ }^{10}$. Su figura política es de una magnitud que

\footnotetext{
${ }^{9}$ En efecto, es necesario reflejar las condiciones que las hacen aprovechables para la historia, las inscripciones son fuentes excepcionales pero exigen un esfuerzo crítico para reconstruir las intenciones de los autores. Cf. J. DURLIAT, Epigraphie et société. Problèmes de méthode: epigrafía medievale greca e latina. Ideologia et funzione, Spoleto, 1995, pp. 169-196.

${ }^{10}$ Ansur Díaz se casó de segundas nupcias con la condesa Justa Fernández, con quien tuvo dos hijos Diego Ansúrez y Gonzalo Ansúrez. Al morir ésta dejó todos sus bienes, en caso de fallecimiento de sus hijos, a Pedro Ansúrez.
} 
alcanza dos reinados; será uno de los magnates principales de la curia de Alfonso $\mathrm{VI}^{11}$, al cual acompaña en su destierro en Toledo; posteriormente servirá en la curia de la reina Urraca. Es el personaje de mayor peso de la curia por su proximidad al rey en la etapa leonesa del reinado (1062-1072). La cancillería real dispone su nombre destacado en la columna destinada a la curia donde, a excepción de algunos documentos en que figura como mayordomo, aparece con el título genérico de "comes" ${ }^{2}$. Alfonso VI le confia asuntos importantes como el viaje a Granada en 1074 para exigir al taifa Abd Allah su incorporación a la nómina de los taifas tributarios del rey leonés. Aparece en el fuero de Nájera completando su papel político con sus intervenciones judiciales ${ }^{13}$. Conde en Carrión (desde 1074) y Saldaña, por encomendación del rey, desde 1077 añade la tenencia de San Román de Entrepeñas. A estas tenencias se suman los territorios gobernados de $\mathrm{Za}$ mora y Toro en 1084 y La Liébana, así como Melgar, Simancas, Cabezón y Torremormojón ${ }^{14}$. Su biografía está unida, ante todo, a la repoblación de la ciudad de

${ }^{11}$ El primer monográfico dedicado a este personaje es un breve estudio publicado en 1947 por Casiano GARCÍA RODRÍGUEZ, "Pero Ansúrez de Sahagún", Archivos Leoneses, $\mathrm{n}^{\circ} 2$ (1947), pp. 119-124. La biografía tradicional sobre este personaje se debe a J. RODRIGUEZ, Pedro Ansúrez, Diputación de León, León 1966. En ella hace un retrato de su linaje, su familia así como de sus relaciones políticas en la corte de Alfonso VI. Sobre su actuación en la repoblación de Valladolid y su desarrollo en la Edad Media vid. P. MARTÍNEZ SOPENA, Una historia de Valladolid. El Valladolid medieval, Ayuntamiento de Valladolid, Valladolid, 2008. Este mismo autor da ciertas pinceladas sobre su actuación en la ocupación del Duero en La irradiación de la aristocracia en tiempos de Alfonso VI, en Alfonso VI y su legado. Actas del Congreso Internacional Sahagún 29 de octubre-1 noviembre de 2009, León 2013, pp. 70-71. Recientemente contamos con un extenso estudio sobre el perfil político de este personaje y su influencia en la curia regia realizado por Andrés BARON FAJARDO, El conde Pedro Ansúrez. Poder y dominio aristocrático en León y Castilla en los siglos XI y XII, Colección Historia Medieval, ed. Glyphos, Valladolid, 2013.

${ }^{12}$ Según Menéndez Pidal, en 1072, tras la muerte de Sancho y el supuesto juramento de Alfonso VI ante los nobles castellanos, Ansúrez fue nombrado alférez del rey, cargo que, en realidad, nunca ostentó. Cf. L. SUÁREZ FERNÁNDEZ, Historia de España, antigua y media, ed. Rialp, Madrid, 1976, p. 483. Ciertamente Ansúrez aparece frecuentemente en la documentación de Alfonso VI y de su hija Urraca como confirmante, dada su condición de magnate y de hombre de confianza del rey pero ostentando únicamente su título condal hasta 1117, fecha probable de su muerte. El único cargo cortesano que se le conoce data de 1067 cuando aparece como mayordomo de Alfonso VI. Cf. A. GAMBRA, Alfonso VI, Cancillería, curia e imperio, I. Estudio, Centro de Estudios e investigación San Isidoro, $\mathrm{n}^{\circ}$ 62, León, 1997, p. 574. Así mismo, las referencias a que pudiera ser ayo de Urraca (así lo afirma Elena LOBATO, Urraca I, La corte castellana leonesa en el siglo XII, Palencia, 2000, p. 31) parece estar descartado Cf. Carmen PALLARES, E. PORTELA, La reina Urraca, ed. Nerea, San Sebastián, 2006, p. 25. La crónica de Jiménez de Rada lo representa como paradigma de la fidelidad digna de un vasallo y de la lealtad aristocrática.

${ }^{13}$ Cf. GAMBRA, Alfonso VI, p. 583.

${ }^{14}$ Cf. C. M. REGLERO DE LA FUENTE, El señorio de los montes de Torozos: de la repoblación al becerro de la behetrías (s. X-XIV), Valladolid, 1993, p. 86; J. de SALAZAR Y ACHA, La Casa del Rey de Castilla y León en la Edad Media, Madrid, Centro de estudios constitucionales, 2000, p. 353. 


\section{MARÍA ENCARNACIÓN MARTÍN LÓPEZ \\ LA MEMORIA DEl linAJE ANSÚREZ: El SEPUlCRO DE FERNANDO PÉREZ EN GORdALIZA DEL PINO (LEÓN)}

Valladolid a la que llegó cuando ésta era un recinto defensivo. En 1103 desaparece de la curia leonesa para trasladarse a la corte de Armengol V, casado con su hija, cuando éste muere en batalla contra los musulmanes ${ }^{15}$. Desde 1104 los almorávides se habían hecho fuertes en el territorio de Fraga y el condado de Urgel peligraba. La actuación de Pedro Ansúrez en Urgel, como abuelo del conde Armengol VI, aún niño, fue imprescindible para defender el territorio. Así participó en la conquista de Balaguer (1106), ciudad que se convirtió en nueva capital del condado de Urgel. Su última aparición en la documentación fue el 9 de diciembre de 1117.

Por su parte Eylo Alfonso, primera mujer de Pedro Ansúrez, pertenece a un linaje antiguo e igualmente de peso político. Hija del conde Alfonso Muñoz, señor de Cea, y de Aldonza González, aporta al matrimonio propiedades en el valle de Trigueros, procedentes de su madre Aldonza González y en Tierra de Campos. Con su matrimonio se unen propiedades a lo largo del Pisuerga, un territorio estratégico políticamente en este periodo, contribuyendo a fortalecer las relaciones internas entre ambos linajes ${ }^{16}$. La etapa de su vida mejor documentada es cuando, junto a su marido, repuebla Valladolid y posteriormente en su papel de fundadora de tres hospitales y de las iglesias de San Sebastián y San Nicolás de dicha ciudad, y con su esposo cofundadora de Santa María.

Ambos linajes, Ansúrez y Alfonso, constituyen lo que Reglero denomina "nobleza europeizante, pro-navarra y filocluniacense". Efectivamente, será la actuación de esta nobleza la que facilite la formación de la red de prioratos cluniacenses en todo el reino ${ }^{17}$. El matrimonio tuvo cinco hijos: Mayor Pérez ${ }^{18}$, María Pérez ${ }^{19}$, Urraca Pérez ${ }^{20}$, Alfonso Pérez y Fernando Pérez.

${ }^{15}$ Cf. SUAREZ, Historia de España, p. 528.

${ }^{16}$ Apunta Justiniano Rodríguez la posibilidad de que esta familia radicase habitualmente en Sahagún, donde se criaron sus hijos, tal y como lo expresan Citi Alvarez y su mujer Froilo en un documento de 31 de julio de 1102. Cf. J. RODRIGUEZ, Pedro Ansúrez, pp. 53-57.

${ }^{17}$ Cf. Carlos M. REGLERO DE LA FUENTE, Cluny en España. Los prioratos de la provincia y sus redes sociales (1073-ca 1270), Centro de estudios e investigación "San Isidoro", León 2008, p. 234.

${ }_{18}$ Mayor Pérez, debió ser la primogénita del matrimonio. Casada con Alvar Fáñez y posteriormente con Martín Pérez, señor de Tordesillas, se la conoce por su inquietud fundadora y su generosidad con los monasterios de San Isidro de Dueñas, San Román de Entrepeñas, Retuerta y Santa María de la Vega. Así mismo apoyó como otros tantos nobles de la época, el asentamiento de comunidades cistercienses.Cf. Á. NEILA MAJADA, "La hija mayor de los condes Pedro Ansúrez y Eilo Alfonso", Los cántabros, no 8 (2010), pp. 68-79.

${ }^{19}$ María Pérez, la segunda hija, se casó con Armengol V de Urgel. La muerte de Armengol trajo consigo la rebeldía de la población de Balaguer haciendo peligrar la estabilidad del territorio. Pedro Ansúrez se instalará con su mujer en la corte para reestablecer el orden político y asegurar el trono de su nieto. 


\section{MARÍA ENCARNACIÓN MARTÍN LÓPEZ

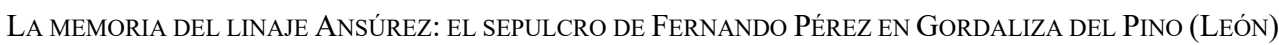

Naturalmente nuestro interés reside en los hijos varones. Alfonso muere prematuramente y será enterrado en el monasterio de Sahagún (León). Sobre su enterramiento hablaremos más adelante. Respecto a Fernando Pérez es escasa la información que los documentos nos ofrecen. Se casó con Elo Rodríguez ${ }^{21}$, fue titular del señorío de San Román de Entrepeñas, Mave, valle de Santullán, Mudá y Cervera de Pisuerga. Como titular de la abadía y descendiente de su fundador y principal propietario es posible que Fernando haya sido el artífice de ceder las raciones de San Román a Cluny, acontecimiento que acaeció entre 1116 y $1120^{22}$.

De su actividad política en el reino apenas tenemos noticias documentales. Las primeras menciones que se conservan de la figura de Fernando Pérez datan del año 1095, momento en el cual tenía lugar la dotación y consagración de la Abadía de Santa María la mayor de Valladolid. Aparecerá como confirmante en otros dos diplomas de este mismo monasterio junto a su mujer Elo Rodríguez. Conocemos la donación que hiciera junto a su mujer Elo de la mitad de la propiedad de Recueva el 29 de abril de $1120^{23}$. Aparece en las datas sincrónicas como "dominante castellum Sancto Romano" o "imperat Sancti Romani"24 hasta el 6 de marzo de 1133. A partir de esa fecha su nombre desaparece de la documentación. No deja de llamar la atención la escasa información que sobre este personaje tenemos teniendo en cuenta que, tras el fallecimiento de su padre, se convierte en la cabeza del linaje.

${ }^{20}$ Urraca Pérez, tercera hija, se casó con el conde Sancho. Fue señora de los lugares de Villa Abduz y Villa Alan, territorio de Sahagún, que heredará su hija Elvira.

${ }^{21}$ Este personaje femenino es controvertido. Debo agradecer las sugerencias de Jaime Salazar y Acha, experto en genealogía quien me ha dado una nueva aportación que cambiaría la identificación que yo aporto a este trabajo y que dejo abierta para posteriores investigaciones. Según Salazar y Acha Elo (Eilo) Rodríguez es la verdadera descendiente de Pedro Ansúrez, nieta suya para ser exactos, hija de María Pérez, primogénita de Pedro Ansúrez. María Pérez se casó dos veces: su primer marido sería Rodrigo Ordoñez, Alférez Real (1081-1087), hermano del conde García Ordoñez, y después se casó con el conde Armengol de Urgel, teniendo sucesión con sus dos maridos. Del primero tuvo una hija llamada Eilo, como su abuela materna, y otra llamada Anderquina, como la abuela paterna, y del segundo al heredero del condado de Urgel, que sería protegido por su abuelo Pedro Ansúrez. Esta Eilo Rodríguez, nieta del conde Ansúrez, sería la mujer de Fernando Pérez y la base de su conexión con los Ansúrez. Esta filiación se confirma, según Salazar y Acha, en un documento concedido por Ansúrez a la iglesia de Santa María de Valladolid en 1114, donde aparecen confirmando los tres hermanos (Eilo Rodriguez, Anderquina y Armengol).

${ }^{22}$ El monasterio estaba dividido en raciones por lo que o bien el conde o bien sus herederos, ceden éstas a Cluny. Cf. REGLERO, Cluny en España, p. 250.

${ }^{23}$ Cf. J. M. RUIZ ASENCIO, Irene RUIZ ALBI y Mauricio HERRERO JIMENEZ, Colección documental de San Román de Entrepeñas (940-1608), Colección fuentes y estudios de historia leonesa, $\mathrm{n}^{\circ} 86$, León, 2000, $\mathrm{n}^{\circ} 14$.

${ }^{24}$ Cf. RUIZ ASENCIO, RUIZ ALBI y HERRERO JIMENEZ, Colección documental de San Román de Entrepeñas, ${ }^{\circ}$ 14, 15, 17, 19, 21. 
Es posible que a la muerte de Pedro Ansúrez la preeminencia de sus sucesores al frente del grupo no fuera aceptada, de ahí que las noticias sobre nuestro personaje sean escasas. Todo parece indicar que la actividad política de Fernando Pérez se circunscribe al norte de Palencia perdiendo el linaje Ansúrez la posición de influencia dentro de la curia regia que había tenido con su padre. De él nos dice Justiniano Rodríguez es el reflejo de "la triste idea de los hijos caídos desde un alto pedestal familiar" 25 . No puede negarse, afirma Barón Fajaldo, que con el paso del tiempo los descendientes directos de Pedro Ansúrez debieron ocupar una posición de privilegio, pero también es cierto que la documentación no ha dejado muchas evidencias que muestren esa más que posible presencia de estos últimos al lado de su antecesor ${ }^{26}$.

Ciertamente, a juzgar por la documentación, la coyuntura política del siglo XII no favoreció al linaje Ansúrez. Los nuevos parientes reales, Enrique de Lorena y Raimundo de Borgoña, ocuparán las tenencias tradicionales de los Alfonso, lo que pudo motivar desavenencias con Pedro Ansúrez y su posterior ausencia del reino. Sea o no así, lo que parece incuestionable es la transformación definitiva del mapa territorio que se manifiesta incluso en los propios monasterios.

\subsection{Muerte de Fernando Pérez la campaña contra Andalucía de 1133}

A juzgar por la inscripción, Fernando Pérez se trasladó con Alfonso VII a Andalucía donde encontrará la muerte. Realmente no tenemos más que esta noticia directa sobre su intervención en la expedición ya que la documentación no aporta información alguna de su presencia en las huestes alfonsíes.

En 1133 el fortalecimiento en el interior de sus reinos permitirá a Alfonso VII iniciar la contraofensiva islámica. El pacto con Zafadola, gobernante de Zaragoza, le permitió elaborar una nueva estrategia que le permita abordar sus aspiraciones militares. Zafadola se compromete a reconocer como rey al monarca leones y se convierte en milites regis, recibiendo en contrapartida una serie de fortalezas en las fronteras toledanas.

La primera gran expedición contra Andalucía fue organizada por Alfonso VII en 1133. Para ello en enero de ese año se traslada a Sahagún para obtener dinero de los monjes para su campaña. La rebelión de Gonzalo Peláez, en Asturias, retrasa los preparativos pero no será suficiente para alterar el rumbo de la expedi-

\footnotetext{
${ }^{25}$ Cf. J. RODRIGUEZ, Pedro Ansúrez, 67.

${ }^{26} \mathrm{Cf}$. BARON FAJARDO, El conde Pedro Ansúrez.
} 
ción ${ }^{27}$. Una vez solucionado los asuntos internos Alfonso prosigue con los preparativos de la campaña contra los almorávides, trasladándose a Carrión (Palencia) y luego a Palencia en abril, donde convoca a los nobles para la batalla. Allí, posiblemente, se encontraría con Fernando Pérez quien se une a la expedición junto a otros magnates y prosiguen su itinerario hacia Guadalajara.

El ejército alfonsí se concentra en Toledo en el mes de mayo, cruza el Tajo y se divide en dos: una facción mandada por Rodrigo González entra en Andalucía por el puerto del Muradal hacia Jaén mientras que la facción de Alfonso VII cruza por el puerto del Rey, se reúne el ejército en el lugar llamado Gallello, de identificación desconocida en la provincia de Jaén. Alfonso VII perseguía el dominio meridional de la Península, en su proyecto estaba ya la idea de ser "imperator Hispaniae" ${ }^{28}$. Con los andaluces bajo su imperio las circunstancias políticas y económicas permitirían desarrollar su proyecto. Cuatro meses estuvieron las tropas cristianas en Andalucía. Así que podemos suponer que Fernando Pérez, a falta de una fecha concreta, moriría entre mayo y agosto de 1133.

\subsection{La sepultura}

Resulta llamativo que un miembro del linaje Ansúrez se haya enterrado en una localidad de Tierra de Campos y no en el cercano monasterio de Sahagún donde se hallaba la tumba de Alfonso Pérez y con quien mantenía una estrecha relación, o aún más, que no se trasladara su cuerpo a San Román de Entrepeñas, lugar donde ostentaba su señorío.

El monasterio de San Facundo y San Primitivo era el predilecto de Alfonso VI al que había favorecido y que destinó para su sepultura. Pedro Ansúrez, así mismo, elegirá el cenobio como lugar de enterramiento del linaje mediante donación y entrega de su cuerpo y el de su mujer ${ }^{29}$. El documento fue firmado el 13 de abril de 1101, por el que donan, además de sus cuerpos, la heredad de Moratinos,

${ }^{27}$ Cf. M. RISCO, España Sagrada, 38, Madrid, 1793, p. 141; A. RECUERO ASTRAY, Alfonso VII, 36, pp. 118-121; M. Á. LADERO QUESADA y J. MATTOSO, La reconquista y el proceso de diferenciación política (1035-1217), Espasa Calpe, Madrid, 1998, p. 212.

${ }^{28}$ Cf. M. PÉREZ GONZÁLEZ (ed. y trad.), Crónica del Emperador Alfonso VII, León, Universidad de León, 1997. Sobre la inspiración de esta crónica y las influencias vid. Ch. GARCIA, "La Chronica Adefonsi Imperatoris y las crónicas eclesiásticas medievales: influencias y mimetismos", E-spania revue interdisciplinaire d'études hispaniques médiévales et modernes, junio 2013.

${ }^{29}$ Realmente el vínculo con el monasterio de Sahagún parte de la familia de la condesa Eylo, ya que su padre Alfonso Muñoz, era poseedor del señorío de Cea. Sobre la relación de los Ansúrez con Cluny vid. REGLERO, Cluny en España, pp. 249-254. 
así como su parte en la villa Don Sanzo y Santa María de Camraso. Un año después, el 13 de julio de 1102, el monasterio dona a Pedro Ansúrez y la condesa Eylo varias heredades en San Román de Entrepeñas, y una divisa en Villota, a su vez recibe del conde una heredad en Villada ${ }^{30}$. Sin embargo, como ocurre en tantas ocasiones, este deseo no se cumplió y el conde fue enterrado en Santa María la Mayor de Valladolid junto a su segunda mujer Elvira Sánchez, mientras que se desconoce el lugar de enterramiento de la condesa Eylo $(1113)^{31}$. Quien sí se enterró en Sahagún es su hijo Alfonso Pérez, prematuramente fallecido en 1093, sin que quedara de él nada más que la conmemoración de su sepultura, con una sencilla inscripción: In era MCXXXI, VI idus decembris, obiit An[fos Petri Assuriz comitis] et Eilonis comitisse carus filius ${ }^{32}$.

A la muerte de Alfonso Muñoz, será Pedro Ansúrez quien cuide los intereses del linaje Alfonso en el territorio. En 1085 el abad Hugo de San Pedro de Cluny, estando presente doña Justa Fernández, vende a Pedro Ansúrez las posesiones que habían pertenecido a dicha condesa. Los bienes eran: las mitades que tenía en Fuentes de Valdepero, en Monzón, en Vega de Ruiponce, en Fuentes de Berroz, en Villasner y en Castrillo así como Villanueva de Galindo Núñiz, por dos mil quinientos sueldos de precio ${ }^{33}$. Entre 1088 y 1091 Pedro Ansúrez hace dona-

\footnotetext{
${ }^{30}$ Cf. HERRERO DE LA FUENTE, Colección diplomática del monasterio de Sahagún, III, $\mathrm{n}^{\circ} 1069 \mathrm{y} \mathrm{n}^{\mathrm{o}} 1085$.

${ }^{31}$ Cf. J. RODRIGUEZ, "En torno a la lauda sepulcral del conde Pedro Ansúrez”, Boletín del seminario de estudios de arte y arqueología, BSAAA, tomo 27 (1961), pp. 337-342. J. VALDEON BARUQUE, El monumento al conde Ansúrez, Consejería de Cultura y Turismo, Valladolid, 1992.

${ }^{32}$ Cf. GOMEZ MORENO, Catálogo monumental de España. Provincia de León, $1^{\circ}$ ed. Ministerio de instrucción pública, Madrid 1925, reed. Facsímil Nebrija, León, 1979, p. 348; J. RODRIGUEZ, Pedro Ansurez, p. 57. El sarcófago es digna pieza del alto linaje al que pertenecía el difunto. El sarcófago cuenta con un total de nueve inscripciones, calificadas dos como funera y siete explanationes que identifican los personajes representados. Su epitafio, hoy parcialmente desaparecido, fue leído íntegramente por Sandoval: El 6 de diciembre de 1093, murió Alfonso hijo querido del conde Pedro Ansurez y la condesa Eylo. El epitafio es necrológico, esto es, nos da la noticia de la muerte aunque lo normal, al estar inscrito en el sarcófago, sería que fuera sepulcral y nos afirmara — Hic requiescit - que ahí está enterrado Alfonso Pérez. Desde el punto de vista estilístico, el conjunto iconográfico de esta pieza ha llamado la atención de los investigadores de la historia del arte. Recientemente ha sido objeto de un estudio riguroso tanto desde el punto de vista iconográfico como desde el epigráfico por Alicia MIGUELEZ CAVERO titulado La impaginatio como punto de partida: la relación entre texto e imagen en la cubierta del sarcófago de Alfonso Pérez procedente de Sahagún: Impaginatio, León, 2011, pp. 74-97. Sobre la tipología de los funera vid. V. GARCIA LOBO, La catedral de León, centro de producción publicitaria, en Congreso Internacional "La catedral de León en la Edad Media", coord. J. Yarza, M. Herráez, G. Boto, León, 2004, pp. 59-75.

${ }^{33}$ La condesa había estado casada con el conde Ansur Díaz. Cuando se tomó la decisión de vender los bienes que había dejado en España la condesa acordó que antes que a nadie se le ofreciese a su hijastro Pedro. Cf. RUIZ ASENCIO, Colección documental de la catedral de León, $\mathrm{n}^{\circ}$ 1237.
} 
ción de todas estas propiedades junto con Villazanzo, que había heredado de su padre, y la villa de Gordaliza de Illis Matis (identificada como Gordaliza de Pino) que era de su mujer Eilo, a la sede catedralicia ya que en 1091 la catedral de León permuta con la condesa Teresa las heredades de Fuentes de Valdepero a cambio de Villazanzo, en Tierra de Campos, que había heredado de su marido el conde Gómez Díaz ${ }^{34}$. Así pues, Gordaliza pasaría del ámbito de influencia de los linajes Ansúrez-Alfonso al dominio de la catedral.

En consecuencia, se nos hace difícil, pero no imposible, justificar el enterramiento del cabeza del linaje en esta localidad y no en San Román de Entrepeñas o el monasterio de Sahagún. La fábrica de la iglesia mudéjar que hoy conocemos no estaría iniciada y en consecuencia el edificio antiguo no correspondería a la altura social de acoger la sepultura de un Ansúrez.

El hecho de enterrar un miembro de un linaje tan importante para Castilla y León en una iglesia de tan poco relieve en ese momento solo tiene una razón de ser: la provisionalidad de dicho enterramiento. Esto nos lleva a plantear los hechos históricos de otra manera. Posiblemente Fernando Pérez fuera herido, y no muerto, en la batalla de Andalucía, pero la gravedad las heridas producen su muerte estando en Tierra de Campos lo que obliga a un enterramiento provisional $^{35}$ en la iglesia de Gordaliza del Pino mientras se disponía un enterramiento definitivo en su abadía de San Román de Entrepeñas, hecho que no sucedió nunca. Lo que nos llevaría a otra pregunta ¿por qué su descendencia no realizó el traslado?

\section{LA INSCRIPCIÓN: ANÁLISIS Y FUNCIÓN}

El monumento funerario está constituido por la representación pictórica del caballero y por la inscripción que explica de quién se trata. Como ya se ha dicho anteriormente la inscripción es una crónica más que un epitafio ya que su cometido no es únicamente informar sobre quien está enterrado sino que nos narra una serie de acontecimientos ajenos al finado.

\footnotetext{
${ }^{34}$ Cf. RUIZ ASENCIO, Colección documental de la catedral de León, no 1254 y 1262.

${ }^{35}$ Sobre su sepultura original nada sabemos. Carecemos de noticias descriptivas pero, a juzgar por la sepultura de Alfonso Pérez, ¿habría que pensar en un enterramiento similar? El hecho de caer en batalla en Andalucía serviría para que afirmemos la existencia de una inscripción conmemorativa de la muerte y de los hechos bélicos. Desconocemos el epitafio sepulcral original pero no parece descabellado pensar que parte del texto que hoy contemplamos proceda de aquel, concretamente la cláusula que narra la muerte en combate.
} 
Analizaremos los elementos constitutivos de la inscripción tanto externos como internos. Unos y otros esclarecerán la época y las razones de su confección así como la autoría de este mensaje y su intencionalidad.

\subsection{La escritura}

De todos los elementos que constituyen la forma de una inscripción, sin duda, el más importante es la escritura y ello porque, junto con las fórmulas, nos permite aproximarnos a la fecha de ejecución de un epígrafe.

La inscripción está realizada en escritura gótica minúscula de buena factura y evolucionada. Este tipo de escritura aparece en el ámbito epigráfico en el siglo $\mathrm{XV}$, aunque sus inicios debemos remontarlos a finales del siglo XIV ${ }^{36}$. La escritura minúscula no es propia de inscripciones, que utilizan las mayúsculas, más acordes con sus caracteres funcionales de monumentalidad y legibilidad. Su uso epigráfico tiene su origen a partir de la escritura de códices, por imitación, concretamente en la variedad gótica denominada littera textualis, caracterizada por su gran formalismo y una estética de contrastes muy marcados. En 1400, de forma homogénea y generalizada, se abandonan las formas mayúsculas para adoptar los caracteres minúsculos ${ }^{37}$. La gótica minúscula presenta una forma gráfica próxima a la escritura libraria. La homogeneidad es casi completa, salvo en alguna grafía, como la "e" que permanece abierta en las inscripciones, mientras que se presenta cerrada en los códices, y en los nexos, que no se prodigan tanto en los epígrafes, para facilitar su lectura. Esta escritura evoluciona a lo largo del periodo de vigencia, esto es, hasta el siglo XVII ${ }^{38}$. A diferencia de los libros donde pronto adoptan formas humanísticas redondas, en las inscripciones la gótica continúa utilizándose en convivencia con las escrituras humanísticas, pero evolucionando a formas cada vez más quebradas. La principal transformación en la morfología de esta escritura radica en el desarrollo de los astiles y los caídos y en el amaneramiento de las

\footnotetext{
${ }^{36}$ Conocemos con certeza dos inscripciones escritas en gótica minúscula a finales del XIV en Valencia. Cf. F. GIMENO BLAY, Materiales para el estudio de las escrituras de aparato bajomedievales. La colección epigráfica de Valencia, Epigraphik, Viena, 1990, pp. 195-215.

${ }^{37}$ Es notable la generalización de este tipo de escritura en todas las regiones que hemos estudiado en España. La gótica mayúscula queda marginada a unos pocos ejemplos, como es, el caso del monasterio de Sobrado de los monjes donde en la capilla de la Magdalena se conserva el sepulcro con el epitafio del caballero Arias Vazquez de Vaamonde, fallecido en1400, realizado en caracteres mayúsculos.

${ }^{38}$ Sobre la evolución de la gótica minúscula vid. M. E. MARTÍN LÓPEZ, "La escritura publicitaria en la Península Ibérica, Siglo XV", en Inschrift unde material Inschrift und Buchschrift. Fachtagung für mittelalterliche und neuzeitliche Epigraphik, München, 1999, pp. 190-193.
} 
formas en general. En efecto, desde la segunda mitad del siglo XV se observa la geminación de los astiles primero, de los caídos después. Geminación que se desarrollará en el XVI y será característica la incurvación y estilización de dichos trazos en el XVII.

En el caso del monumento funerario de Fernando Pérez la escritura es una gótica minúscula de buena factura, de módulo regular que nos hace pensar en una mano ejecutora experta. El conjunto escrito presenta los caracteres quebrados y con tendencia a la verticalidad propia del siglo XV. A estas características debemos añadir la tendencia a rematar los trazos suavemente para mitigar la rigidez de esta escritura. Esta característica es propia de la evolución que experimenta la gótica en la segunda mitad de siglo. Este margen cronológico podemos concretarlo y nuevamente serán los elementos gráficos los que nos ayuden a precisar la cronología. Los astiles no se han desarrollado suficientemente para tender a la geminación general. No obstante se observa una geminación incipiente en algunas letras. Este dato permite concretar la realización de la inscripción entre $1470 \mathrm{y}$ 1500, puesto que será en el último tercio de siglo cuando aparece la geminación de astiles y caídos. Ciertamente las características morfológicas señaladas presentan sus alteraciones sobretodo en el ámbito rural, más lento en la evolución gráfica pero este no es el caso puesto que se trata, a juzgar por el resultado global del conjunto funerario, de una obra realizada por personal experto.

\subsection{El texto, sus peculiaridades y tipología}

La clasificación tipológica de esta inscripción no es fácil. En un principio, y ateniéndonos a la cláusula notificativa "aquí yaz”, la inscripción se clasificaría de funeraria, obvio si va vinculada a un monumento funerario. El grupo de inscripciones funerarias es el más heterogéneo y numeroso de los grupos epigráficos: epitafios sepulcrales, epitafios necrológicos, intitulationes de sepultura, tituli proprietatis, crónicas funerarias, son algunos de los tipos que catalogamos como " $f u$ nera".

La inscripción de Fernando Pérez no es una inscripción típica al uso que guarde la formulística establecida. Realmente no encaja en ninguno de los tipos señalados, al menos de una forma íntegra. Podría parecer un epitafio sepulcral puesto que su fórmula inicial es la notificativa "aquí yaz" propia de éstos, cuya función es señalar el lugar de enterramiento de un personaje: Aquí yaz el fyo de don Per Ansurez e de la condesa donna Yelo. Pero se aleja de los convencionales formularios y a diferencia de un epitafio sepulcral cuyo objeto es identificar no 
solo la sepultura sino el difunto y la fecha de su muerte, aquí estos elementos no aparecen, dando como única identificación solo la filiación "hijo del conde Pero Ansurez y la condesa Elo".

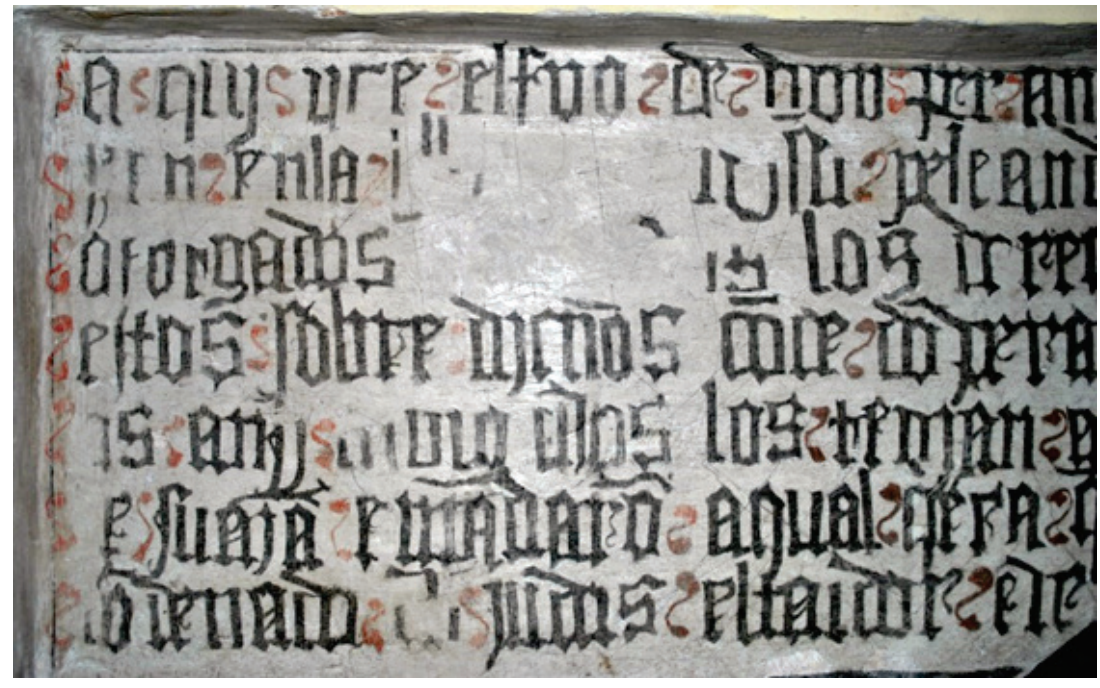

El resto del formulario pasa a ser una narratio o crónica y será la primera cláusula de dicha narratio donde se nos determina la causa de la muerte en batalla - el qual morió siendo alfereze del rey en la [batalla] peleando contra los moros-, que identifico como la primera campaña contra Andalucía en 1133.

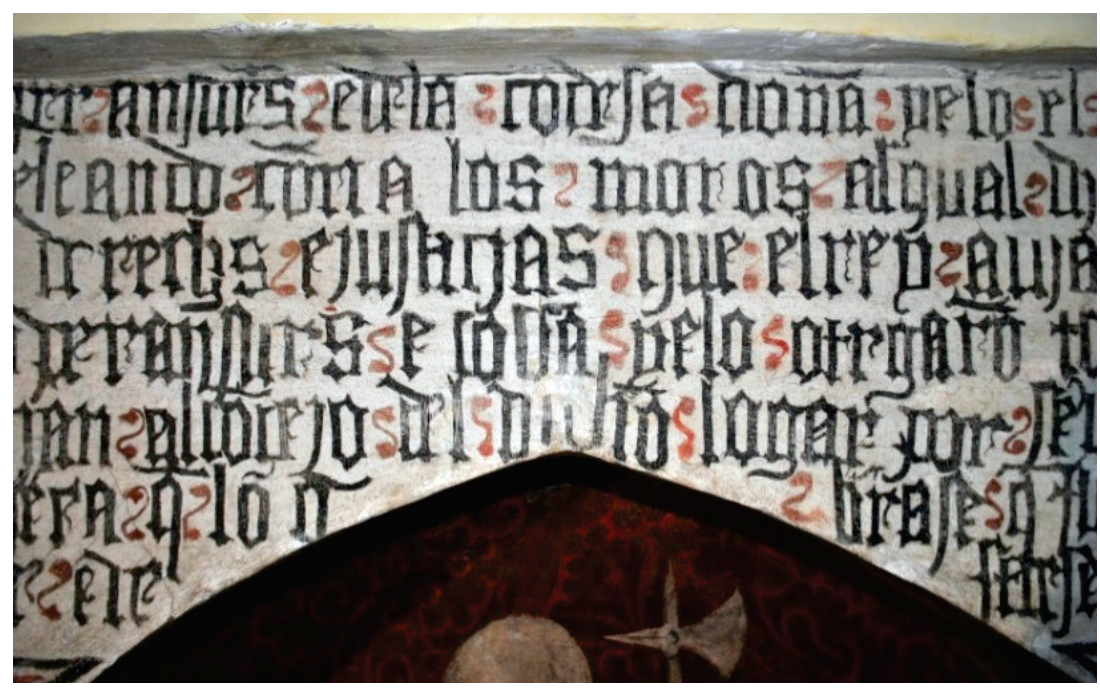

Aunque la inscripción nos dice que detentaba el cargo de alférez esto no es así, en ningún momento aparece en la documentación alfonsí con este cargo ${ }^{39}$. Se

${ }^{39}$ Para la relación de cargos palatinos de este periodo son de referencia las siguientes obras: P. RASSOW, Die Urkunden kaiser Alfons VII von Spanien, Berlín, 1929, pp. 364-365; RECUERO ASTRAY, Alfonso VII Emperador, El imperio hispánico en el siglo XII, Centro de Estudios e 
trata del único error histórico que hallamos en el texto y que puede deberse más bien al ánimo de ensalzar al personaje.

La segunda cláusula ya no alude al difunto, sino a su padre, de modo que describe los derechos solariegos que el conde Ansúrez por donación regia tenía sobre el territorio de Gordaliza: al qual dicho conde don Per Ansurez fueron otorgados los derechos e justicias que el rey auia en este lugar de Gordaliza; La cláusula hace mención a un privilegio real dado por Alfonso VI por el que Ansúrez recibe el lugar de Gordaliza. Este posible documento hoy está desaparecido y no se tiene mención alguna en ninguna otra fuente de semejante donación. Pero no por ello debemos dudar de su existencia ni desdeñar el dato que nos da la inscripción puesto que, como ya dije anteriormente, existen otros documentos, como el pleito sostenido por Ansúrez con la villa en 1090 sobre varias propiedades en el territorio ${ }^{40}$ que permiten creer que dicha donación regia pudo existir. Otra opción sería que esas propiedades procedieran de los bienes aportados por su mujer Eylo Alfonso al matrimonio.

La tercera cláusula expositiva habla de un segundo documento, concretamente de una concesión de dichos derechos al concejo por parte del conde: $y$ estos sobre dichos conde don Per Ansurez e condesa Yelo otorgaron todos los sobredichos derechos, ansí como ellos los tenían, al conceio de dicho logar por servicio de Dios e en iluminamiento de su anima.

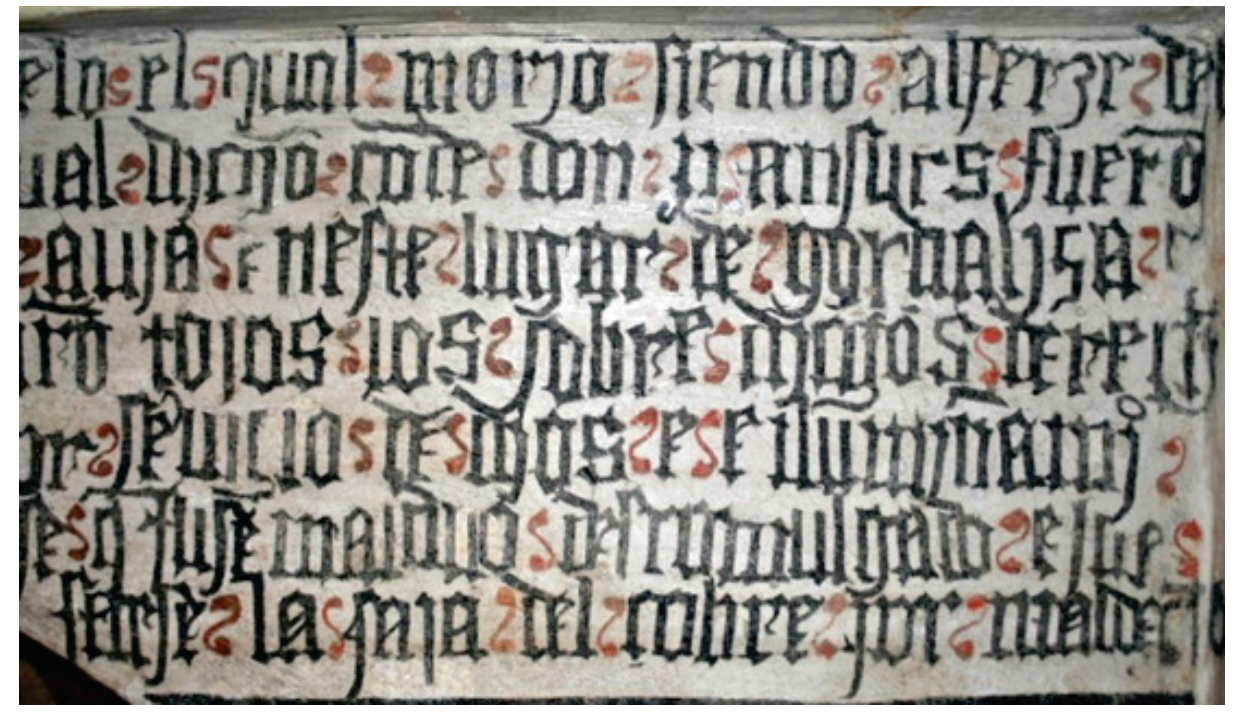

Investigación San Isidoro, 1979; J. SALAZAR Y ACHA, La casa del rey de Castilla y León en la Edad Media, ed. Centro de Estudios políticos y constitucionales, Madrid, 2000.

${ }^{40}$ Cf. HERRERO DE LA FUENTE, Colección diplomática del monasterio de Sahagún, $\mathrm{n}^{\circ}$ 867, pp. 176-177. 


\section{MARÍA ENCARNACIÓN MARTÍN LÓPEZ \\ LA MEMORIA DEl LINAJE ANSÚREZ: El SEPUlCRO DE FERNANDO PÉREZ EN GORdAlizA DEL PINO (LEÓN)}

Una vez más, la cláusula expositiva nos indica la existencia de un documento de donación del conde Ansúrez a la villa de Gordaliza por la que le concede los derechos que poseían sobre ella alegando motivos piadosos. Se trataría de nuevo del pleito mencionado de 1090 ?

Y finalmente el texto se cierra, como si de un cuerpo textual de un diploma se tratase, con las cláusulas penales canónicas y pecuniarias: e mandaron a qual quiera que lo quebrase que fose maldito, descomulgado, e fue condenado con Iudas el traidor, e destrese la saia del cobre por maldición.

Podemos ver claramente la influencia de las fórmulas diplomáticas que nos hacen pensar en la existencia de un documento de concesión que inspire las cláusulas expositivas de esta inscripción. La descripción del acto jurídico, la inclusión de fórmulas textuales como la exposición de motivos - por servicio de Dios e en iluminamiento de su anima - así como las señaladas cláusulas penales podrían ser un trasvase del documento a la inscripción realizado intencionadamente por el ordinator de la inscripción. La relación y transmisión del documento a la escritura publicitaria o inscripción es bastante frecuente ${ }^{41}$ y el uso de ciertas fórmulas diplomáticas así como el asunto jurídico que publicita la inscripción pueden ser indicio de la existencia de un documento en el cual se inspira el autor del epígrafe.

En definitiva, esta inscripción es una chronica funeraria, frecuente en la Baja Edad Media ${ }^{42}$, tipología creada y destinada a perpetuar y revitalizar la memoria

${ }^{41}$ Sobre el trasvase de cláusulas dispositivas y negocios jurídicos de los documentos a las inscripciones vid. M ${ }^{\mathrm{a}}$ E. MARTÍN LÓPEZ, “El documento como fuente para la epigrafía”, en $L a$ documentación para la investigación, Homenaje a J. A. Martín Fuertes, Universidad de León, vol. 1, León, 2002, pp. 361-384. El trasvase así mismo se produce con otros objetos escritos, así de las anotaciones de obituarios a inscripciones en piedra tenemos los ejemplos del claustro de Silos y el panteón real y claustro de San Isidoro, ambos estudiados respectivamente por M ${ }^{\mathrm{a}} \mathrm{E}$. MARTÍN LÓPEZ, "Las inscripciones medievales del claustro de Silos", en Silos. Un milenio. Actas del Congreso Internacional sobre la abadía de Santo Domingo de Silos, II Historia, Estudia Silensia XXVI, Universidad de Burgos-Abadía de Silos, 2003, 469-483; A. I. SUÁREZ GONZÁLEZ, “Del pergamino a la piedra? ¿De la piedra al pergamino?”, Anuario de Estudios Medievales, vol. 33, no 1 (2003), pp. 365-415.

42 El uso de la tipología de crónica la hallamos ya en el siglo XI, concretamente la crónica de fundación del monasterio de San Isidoro por Fernando I y su esposa la reina Sancha en 1063. Cf. $M^{\mathrm{a}}$ E. MARTÍN LÓPEZ, "Las inscripciones del panteón de San Isidoro de León. Particularidades epigráficas", en Homenaje a José María Fernández Catón, León, 2004, pp. 941-972; como tal ha sido recientemente estudiada por Horts BREDEKAMP y Frank SEEHAUSEN, "Das reliquiar als Staatsform. Das Reliquiar Isidors von Sevilla und der Beginn der Hofkunst in León", en Reliquiar in Mittelalter, Hamburger Forschungen zur Kinstgeschichte, V, Akademie Verlag, Berlín, 2011, pp. 137-164, concretamente p. 159. Pero la crónica destinada a ensalzar la imagen del difunto y su contexto histórico lo tenemos magníficamente representado en las crónicas funerarias de los infantes Pedro y Juan conservadas en el monasterio cisterciense de San Andrés de Arroyo. Cf. Ma E. MARTÍN LÓPEZ, "Epigrafía cisterciense: Las inscripciones del monasterio de San Andrés de Arroyo", Cistercium, 208 (1997), pp. 489-508. 
de la nobleza local. Contamos con notables precedentes de esta tipología, tan en uso desde el siglo XIV, como es el caso de la crónica funeraria de Rodrigo Gustioz en Palencia donde se reivindica al difunto y su linaje. En el caso de Gordaliza el texto no trata de exaltar las virtudes del difunto, cuanto de reclamar, y legitimar unos derechos que por ser antiguos, de finales del XI o principios del XII, es necesario recordar.

El por qué se entierra a Fernando Pérez en Gordaliza y no en su señorío de Entrepeñas es algo que desconocemos. Con todo, Gordaliza sigue perteneciendo al linaje de los Ansúrez y quizá el peso de la tradición, por un lado, y la necesidad de un enterramiento provisional, como señalamos, por otro, determinara que fuera en Tierra de Campos, como su hermano, y no en la montaña, donde depositar sus restos mortales.

\subsection{Funcionalidad de la inscripción}

Y esto nos lleva a la última cuestión a tratar aquí, la razón por la cual se realiza este monumento funerario, en el siglo XV. En efecto, a lo largo de nuestro estudio nos planteamos varias cuestiones, a mi juicio, relacionadas entre sí. La primera de ellas por qué se entierra en Gordaliza a un miembro del linaje Ansúrez, la segunda por qué se realiza este monumento funerario a finales del siglo XV, la tercera cuestión se relaciona con el texto, el por qué una crónica funeraria.

La realización del monumento funerario, pinturas e inscripción, en este momento no es casual, ni neutral, el objeto de la inscripción no es únicamente determinar quién es el yacente, prueba de ello es que se preocupa bien poco en dar información del mismo. La intencionalidad del mensaje epigráfico es otra bien distinta: llamar la atención sobre la pertenencia de Gordaliza a la tenencia de un linaje, poner de relieve la concesión de derechos por parte de su señor, Pedro Ansúrez, al pueblo de Gordaliza, y finalmente garantizar la autonomía de gestión de dicho lugar.

Es evidente que el epitafio, más que identificar al difunto lo que hace es reivindicar unos derechos adquiridos en el pasado y que en ese momento, en el siglo $\mathrm{XV}$, los lugareños veían peligrar. Así pues, utilizan todos los medios a su alcance para resaltar los derechos que, de otro modo, podrían caer en el olvido. Pretenden prolongar en el tiempo unos privilegios adquiridos de antaño y que son necesarios publicitar de forma explícita aunque sea mediante un monumento funerario. El enterramiento "provisional” del hijo del conde Ansúrez es para el pueblo de Gordaliza testimonio suficiente que avale la existencia de dichos derechos. 


\section{MARÍA ENCARNACIÓN MARTÍN LÓPEZ

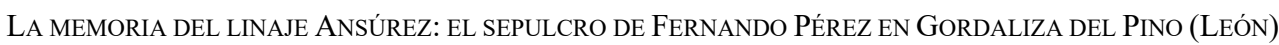

Gordaliza era un señorío territorial, esto es, su titular poseía el dominio del suelo y tenía poder dominical sobre los habitantes. Un dominio que Ansúrez había cedido al concejo, a juzgar por la fórmula epigráfica "otorgaron todos los sobredichos derechos, ansí como ellos los tenían, al conceio". La deducción a partir de esta cláusula, homónima a la documental, hoy desaparecida, es que Gordaliza gozaba de una situación administrativa y económica especial que le daba autonomía de actuación frente al poder regio o señorial. Podríamos decir que existe una cierta jurisdicción concejil? Lo que no cabe duda es que esta realidad contrasta con los intereses de los poderes emergentes, concretamente del poder señorial.

Durante el gobierno de la dinastía Trastámara la institución señorial alcanza su plenitud no solo por las donaciones reales obtenidas para el dominio territorial sino, y lo que es más importante, que ahora se añade el dominio jurisdiccional. Al cambio y crecimiento de los nuevos señoríos se suma el desarrollo de los concejos que pretenden mantener su autonomía ${ }^{43}$. Es más que probable que el trasfondo social y político que encierra esta inscripción sea la pugna entre los distintos estamentos, nobleza por un lado, concejos por otro, en mantener su situación de dominio. En el caso de Gordaliza la villa no estaba dispuesta a perder la capacidad de autogestión sobre su término, ese control sobre sus recursos que venía dado desde tiempos de Pedro Ansúrez, de ahí el afán por reivindicar sus derechos históricos mediante la renovación del enterramiento de un miembro del linaje. Conscientes de ello y de la legalidad jurídica de los mismos esta inscripción publicita su conciencia jurídica.

Y esto nos lleva a una última reflexión: el papel social que tenía la epigrafía para la sociedad del XV-XVI. En Spoleto hace ya veinte años Jean Durliat exponía claramente las conclusiones sobre el valor de la epigrafía como fuente. La epigrafía posee una importancia para la historia en general y para la historia social

${ }^{43}$ Los vasallos aprovechan todos los medios a su alcance para mostrar sus quejas al poder regio, presentan sus denuncias ante las Cortes, reivindican ante el monarca que ponga freno a los abusos de la nobleza. Como breve apunte bibliográfico y un estado de la cuestión vid. I. BECEIRO, "Los estados señoriales como estructura de poder en la Castilla del siglo XV", Realidad e Imágenes del poder en España a fines de la Edad Media, Valladolid, 1988, pp. 293-324, en concreto 304-305; J. VALDEÓN, "Las cortes de Castilla y las luchas políticas en el siglo XV (14191430)", Anuario de Estudios Medievales, 3 (1966), pp. 293-326; M. Á. LADERO QUESADA, "Economía y poder en la Castilla del siglo XV", en Realidad e imágenes del poder en España a fines de la Edad Media, Valladolid, 1988, pp. 371-388. Sobre la evolución del concejo con jurisdicción y otras tipologías vid. Concejos y ciudades en la Edad Media Hispánica, II Congreso de Estudios medievales, Fundación Sánchez Albornoz, Madrid, 1990, especialmente el estudio de J. A. BONACHIA, "El concejo como señorío (Castilla ss. XIII-XV)”, pp. 431-463. 
en particular. Los textos grabados son testimonios de la actividad de una sociedad, son "documentos" como lo son las leyes o los diplomas o las crónicas ${ }^{44}$.

Ciertamente en algunos casos la epigrafía es la fuente principal por no decir la única. En el siglo XV y el XVI la documentación aumenta de forma exponencial. Pero será en algunas ocasiones como esta inscripción donde el pueblo llano exprese sus temores, sus derechos y reivindicaciones. El dosier se completa con el estudio e interpretación correcta de estos textos escritos en escritura publicitaria.

La crónica funeraria de Fernando Pérez aporta datos que hasta hoy la documentación existente no proporcionaba. Nos aporta información sobre documentación desaparecida, un privilegio de Alfonso VI a favor de Pedro Ansúrez, y de una carta de concesión de este último otorgando ciertos derechos al concejo de Gordaliza. Confirma, así mismo, la participación del heredero de los Ansurez en la campaña contra Andalucía en 1133, su muerte y su lugar de enterramiento. Por todo ello el valor de esta inscripción y de todo el conjunto funerario trasciende lo epigráfico hacia un valor historiográfico y cultural.

${ }^{44}$ Cf. J. DURLIAT, "Épigraphie et société. Problèmes de méthode”, en Epigrafía medieval greca e Latina. Ideologia e funcione, Spoleto, 1995, p. 194. 


\section{APÉNDICE DOCUMENTAL}

1133, mayo-agosto.

Crónica funeraria de Fernando Pérez, hijo de los condes Pedro Ansúrez y Eylo, que murió en la primera campaña de Alfonso VII contra Al Andalus y crónica de los derechos otorgados a la villa de Gordaliza por dicho conde.

A. GORDALIZA DEL PINO (LEON), iglesia parroquial de Santa María de Arbas, interior, pared sur, monumento pictórico. Original tardío de la segunda mitad del siglo XV.

Buena conservación.

Aquí: yce:el fyo:de : don per: ansurz: e de la :codesa: dona: yelo: el : qual: morio: siendo: alferze: del

Rey: en la : [batalla] : peleando: cotra los moros: al qual: dicho: code: don: p: ansuez: fuero

Otorgados [todo]s los derecs: e iusticias: que : el rey: auia : en este: lugar: de : gordaliza: y

Estos: sobre dichos code: do per ansurs: e coda: yelo: otrgaron toios: los sobre: dichos: derech

os: ansi: como ellos los: tenían:al coceio: d dicho: logar: por: seuicio: de : dios: e : e iliminami :

De su aia: e madaro: a qual: qera: q lo q brase: q fose maldito: descomulgado: e fue:

Condenado: co iudas:el taidor: e destrese : la : saia: del cobre: por : maldición

Aquí yace el fyo de don Per Ansurez e de la condesa donna Yelo el qual morió siendo alfereze del rey en la [batalla] peleando contra los moros ; al qual dicho conde don Per Ansurez fueron otorgados los derechos e justicias que el rey auia en este lugar de Gordaliza; y estos sobre dichos conde don Per Ansurez e condesa Yelo otorgaron Todos los sobredichos derechos, ansí como ellos los tenían, al conceio de dicho logar por servicio de Dios e en iluminamiento de su anima e mandaron a qual quiera que lo quebrase que fose maldito, descomulgado, e fue condenado con Iudas el traidor, e destrese la saia del cobre por maldición.

Aquí yace el hijo de don Pedro Ansurez y de la condesa doña Eylo, el cual murió siendo alférez del rey en la batalla, peleando contra los moros; al cual dicho conde 
don Pedro Ansúrez fueron otorgados los derechos y justicias que el rey tenía en este lugar de Gordaliza; y estos sobredichos conde don Pedro Ansúrez y condesa Eylo, otorgaron todos los sobredichos derechos así como ellos los tenían al concejo de dicho lugar por el servicio de Dios y en iluminación de su alma. Y mandaron a cualquiera que lo quebrase que sea maldito, excomulgado y condenado con Judas el traidor y diese la saja del cobre por maldición.

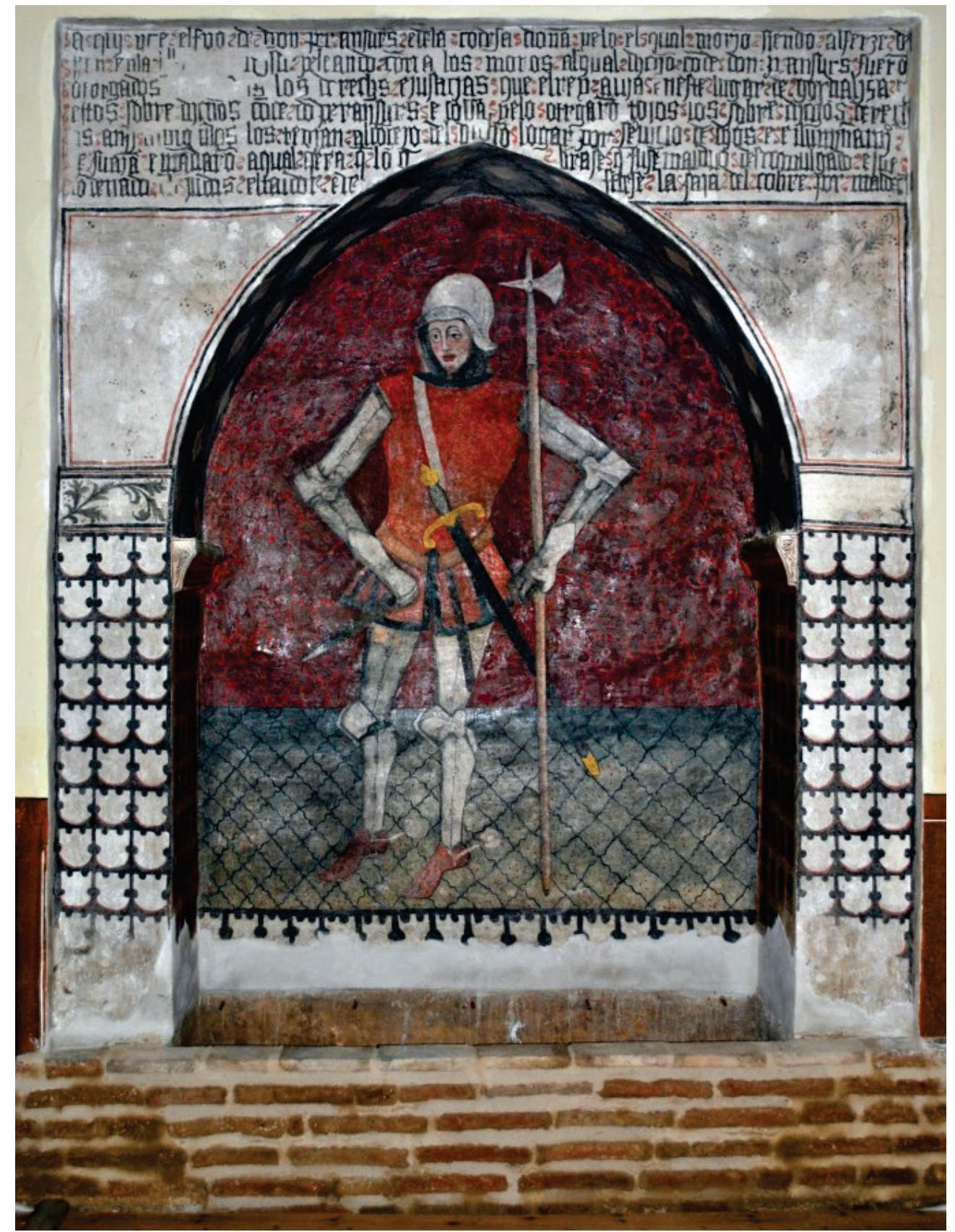

Vista general del monumento funerario de Fernando Pérez, Gordaliza del Pino (León). 